\title{
Comparison and Influencing Factors of Nutritional Status in Rural Left-Behind and Urban Migrant Middle School Students
}

\author{
Yongjing Song ${ }^{1^{*}}$, Yu Lou ${ }^{2 *}$, Jiali $\mathrm{Xu}^{3^{*}}$, Fan Su${ }^{3 *}$, Chaoliang $\mathrm{Mao}^{3^{*}}$, Maolin Yang ${ }^{3 *}$, Yuqiang $\mathrm{Li}^{4 *}$, \\ Jinkui Lu ${ }^{3 * \#}$ \\ ${ }^{1}$ School of Physical Education, Yangtze University, Jingzhou, China \\ ${ }^{2}$ Shangrao No. 4 Middle School, Shangrao, China \\ ${ }^{3}$ School of Physical Education/Research Center for Early Childhood Physical Education and Left-behind Children's Health, \\ Shangrao Normal University, Shangrao, China \\ ${ }^{4}$ School of Physical Education and Health/Key Laboratory of Youth Health Evaluation and Exercise, Intervention of the Ministry \\ of Education, East China Normal University, Shanghai, China \\ Email: 53806902@qq.com, louyu0127@163.com,804265124@qq.com,641683499@qq.com, 450435900@qq.com, \\ maolin127@163.com, liyuqiang-123@126.com, \#lujinkui628@126.com
}

How to cite this paper: Song, Y. J., Lou, Y., Xu, J. L., Su, F., Mao, C. L., Yang, M. L., Li, Y. Q., \& Lu, J. K. (2021). Comparison and Influencing Factors of Nutritional Status in Rural Left-Behind and Urban Migrant Middle School Students. Open Journal of Social Sciences, 9, 1-11.

https://doi.org/10.4236/jss.2021.92001

Received: December 7, 2020

Accepted: February 2, 2021

Published: February 5, 2021

Copyright $\odot 2021$ by author(s) and Scientific Research Publishing Inc. This work is licensed under the Creative Commons Attribution International License (CC BY 4.0).

http://creativecommons.org/licenses/by/4.0/

(c) (i) Open Access

\begin{abstract}
With the development of social economy, people's living standard has been improved. Malnutrition among Chinese adolescents is gradually decreasing, but is still widespread in some rural areas, especially among left-behind adolescents. We compared the nutritional status of rural left-behind and urban migrant middle school students and analysed its influencing factors to provide a scientific basis for the formulation of government policies for health promotion. Stratified cluster random sampling was employed. Participants were 513 urban migrants and 440 rural left-behind middle school students aged 12 - 15 years. The underweight detection rates of the rural left-behind group (boys: $18.6 \%$, girls: $15.4 \%$ ) were substantially higher than that of the urban migrant group (boys: $9.2 \%$, girls: $3.7 \%$ ), and the overweight/obesity detection rates of the urban migrant group (boys: $40.1 \%$, girls: $21.2 \%$ ) were substantially higher than that of the rural left-behind group (boys: $10.2 \%$, girls: $6.6 \%$ ). The prevalence of underweight among rural left-behind middle school students in Shangrao was correlated with parents' education level and monthly household income, and the prevalence of overweight/obesity among urban migrant middle school students in Shanghai was correlated with physical activity.
\end{abstract}

\section{Keywords}

Left-Behind Children, Migrant Children, Nutritional Status, Regression Analysis

These authors contributed equally to this work. 


\section{Introduction}

The health of two particular children populations-rural left-behind children and urban migrant children-is a key public health problem in China. As of December 2018, the total numbers of rural left-behind children and urban migrant children aged 16 years and younger were 6.97 million (Fu \& Chen, 2018) and 14.0663 million (Wei \& Zhang, 2018), respectively. Previous research on the health of rural left-behind children has mainly focused on psychological problems such as depression (Li, 2005), anxiety (Lei, 2014), and loneliness (Jing, 2019); physiological conditions such as anaemia ( $\mathrm{Tu}, 2016)$ and maldevelopment (Mou, Luo, Li, Shuai, \& Liu, 2009); and undesirable behaviours and habits such as smoking (Wang, 2009), compulsive lying (Hu, 2019), and a propensity for violence (Li \& Wang, 2018; Liu, Zhang, Li, Zhai, \& Xu, 2011). Similarly, most studies on the health of urban migrant children have concentrated on psychological aspects such as loneliness (Jiang \& He, 2019; Wang, Liu, Zheng, Liu, \& You, 2017; Liu, Yu, Wang, Zhang, \& Ren, 2014), inferiority complex (Liu, Yu, Wang, Zhang, \& Ren, 2014), emotional sensitivity (Zhou, 2018), anxiety (Zhang, 2018), and a lack of self-confidence (Xiao \& Zeng, 2014). Further, some studies reported that the overweight/obesity detection rates in migrant children have gradually approached that of urban children and exhibited an increasing trend (Lu, Yin, Deng, \& Ji, 2017).

In this study, we compared the nutritional status of rural left-behind and urban migrant middle school students who were registered residents of rural areas and analysed the relevant influencing factors with the hope of providing a scientific basis for the formulation of governmental policies for health promotion among rural left-behind and urban migrant middle school students.

\section{Participants and Methods}

\subsection{Sampling Method}

Sampling was performed using the stratified cluster random sampling method. In April-June 2019, Baoshan, Jiading, and Songjiang were selected from the various districts of Shanghai City, and one middle school was selected from each district. The three selected urban middle schools were attended by 2314 students. Similarly, Wuyuan, Dexin, and Yushan were selected from the various counties of Shangrao-a prefecture-level city in Jiangxi Province-and one rural middle school was selected from each county. The three selected rural middle schools were attended by 1464 students. A total of 513 urban migrant students (accounting for $22.2 \%$ of the urban school population) consisting of 272 boys (53.0\%) and 241 girls (47.0\%) who were registered residents of rural areas were screened from the selected urban middle schools in Shanghai; and 440 rural left-behind students (accounting for $30.1 \%$ of the rural school population) consisting of 226 boys (51.4\%) and 214 girls (48.6\%) who were registered residents of rural areas were screened from the selected rural middle schools in Shangrao. Then 953 left-behind middle school students were selected as the research par- 
ticipants, which were aged 12 - 15 years with a mean age of $13 \pm 0.89$ years. Left-behind middle school students were defined as children/adolescents aged 12 - 15 years who were registered residents of rural areas and had been left behind in rural areas by one or both parents who had migrated to other regions for more than six months (Duan \& Yang, 2008). Migrant middle school students were defined as children/adolescents aged 12 - 15 years who were registered residents of rural areas in provinces (municipalities/regions) other than Shanghai and had migrated to Shanghai and lived together with their parents, who were migrant workers in Shanghai, for more than six months (Kuang \& Xu, 2017).

\subsection{Survey Method}

College student volunteers in each city were selected as investigators. All investigators underwent standardised survey-related training and assessment before performing the survey. Each survey session was performed with students belonging to the same class. Prior to the start of the session, the investigators explained the purpose of the survey and important points to note when completing the survey questionnaire, and provided assurance regarding adherence to the principles of anonymity, confidentiality, and voluntary participation. Responses to general demographic questions in the questionnaire were completed by participants or their guardians, and other information was independently provided on-site by participants with assistance from the investigators. Completed questionnaires were checked by the investigators prior to collection. This study was approved by the ethics committee of the School of Physical Education of Shangrao Normal University, and survey sessions were conducted only after written informed consent had been provided by the participants and their guardians.

\subsubsection{Questionnaire Content}

Questionnaire design was performed based on a review of relevant literature (Liu \& Dai, 2019; Wu, Qiao, \& Hao, 2019). The developed questionnaire had good validity and achieved a Cronbach's alpha value of 0.86 , indicating its internal consistency. The questionnaire content included questions on general demographic characteristics (sex, age, and place of registered residence), family background, and lifestyle behaviours during the past month. Questions regarding family background included the following: 1) Fathers' educational level (primary or below, secondary, or high school/secondary technical or above); 2) Mothers' educational level (primary or below, secondary, or high school/secondary technical or above); 3) Monthly household income in yuan ( $\leq 2000,2001-5000,5001$ - 8000, >8000). Questions regarding lifestyle behaviours during the past month included the following: 1) Engagement in vigorous physical activity (MET value $>6$ )/week (yes, no), and engagement in moderate physical activity ( $3 \leq \mathrm{MET}$ value $\leq 6$ )/week (yes, no) (Hootman, 2009); 2) Number of hours spent watching television/day (0 - 1, $2-3,>3$, never); 3) Number of hours spent on a mobile phone/day $(\leq 1,2-3,>3)$; 4) Number of fast-food meals/week $(\geq 4,2-3, \leq 1) ; 5)$ Number of days on which breakfast was eaten/week $(\geq 4,2-3, \leq 1)$. 


\subsubsection{Physical Examination}

Measurements of body weight and height were performed by researchers using electronic height and weight measuring scales of the same brand and model (HGM300; Shanghai Henggang Instruments Co., Ltd.). During each measurement, the participant was asked to stand barefoot at the centre of the weighing platform, maintain his/her head in an upright position with the superior margin of both tragi aligned at the same level as the superior orbital margin, direct his/her gaze straight ahead, and keep both arms relaxed at his/her sides. Boys wore shorts and girls wore a short-sleeved top and shorts during measurements. Height and body weight measurements were accurately determined to the nearest $0.1 \mathrm{~cm}$ and $0.1 \mathrm{~kg}$, respectively, and used for the calculation of body mass index. Assessment of underweight and overweight was performed in accordance with the Screening Standard for Malnutrition of School-age Children and Adolescents (National Health and Family Planning Commission of the People's Republic of China, Beijing 2014) and Screening Standard for Overweight and Obesity Among School-age Children and Adolescents (National Health and Family Planning Commission of the People's Republic of China, Beijing 2018).

\subsection{Statistical Analysis}

All data were input by double entry using Epidata 3.0, and database verification was performed after data entry. Statistical analyses were performed using SPSS 22.0. Underweight and overweight/obesity detection rates were compared between the rural left-behind group and urban migrant group using $\chi^{2}$-tests. Factors influencing underweight among the rural left-behind participants and overweight/obesity among the urban migrant participants were analysed using logistic regression analyses at a significance level of $\alpha=0.05$.

\section{Results}

\subsection{Comparison of Underweight and Overweight/Obesity Detection Rates between Rural Left-Behind and Urban Migrant Middle School Students}

The underweight detection rates of the rural left-behind group (boys: 18.6\%, girls: $15.4 \%)$ were substantially higher than that of the urban migrant group (boys: $9.2 \%$, girls: $3.7 \%$ ), and the overweight/obesity detection rates of the urban migrant group (boys: $40.1 \%$, girls: $21.2 \%$ ) were substantially higher than that the rural left-behind group (boys: $10.2 \%$, girls: $6.6 \%$ ). When the participants of both groups were classified according to sex and age, differences were only significant among the various weight statuses in the rural left-behind group $(\mathrm{Z}=$ $-3.185, P<0.01$; Table 1).

\subsection{Univariate Analysis of Correlations of Different Family Conditions and Lifestyle Behaviours with Underweight and Overweight/Obesity in Middle School Students}

The correlations between underweight in the rural left-behind group with fami- 
ly-related factors such as the fathers' educational level, mothers' educational level and monthly household income were significant $\left(\chi^{2}=22.805,16.639\right.$ and 29.795, respectively; all $\left.P_{S}<0.01\right)$. In the urban migrant group, the correlation between overweight/obesity and engagement/non-engagement in vigorous physical activity was significant $\left(\chi^{2}=5.523, P<0.05\right.$; Table 2$)$.

\subsection{Logistic Regression Analysis of Correlations of Different Family Conditions and Lifestyle Behaviours with Underweight among Rural Left-Behind Participants and Overweight/Obesity among Urban Migrant Participants}

For the rural left-behind group, a logistic regression analysis was performed by setting weight status (normal $=0$, underweight $=1$ ) as the dependent variable and fathers' educational level, mothers' educational level, and monthly household income as the independent variables-after controlling for age and sex. Results indicated that the underweight detection rates of rural left-behind participants whose fathers had received a primary education or below and those whose fathers had received a secondary education were 4.14 and 2.38 times that of participants whose fathers had received at least a high school/secondary technical education. The underweight detection rate of rural left-behind participants whose mothers had received a primary education or below was 2.17 times that of participants whose mothers had received at least a high school/secondary technical education. Rural left-behind participants with a monthly household income of $\leq 2000$ yuan had an underweight detection rate that was 4.07 times that of participants with a monthly household income of $>8000$ yuan. For the urban migrant participants, a logistic regression analysis was performed by setting weight status (normal $=0$, overweight/obese $=1$ ) as the dependent variable and engagement/non-engagement in vigorous physical activity as the independent variable. Those who did not engage in vigorous physical activity had an overweight/obesity detection rate that was 1.75 times that of those who engaged in vigorous physical activity (Table 3 ).

Table 1. Comparison of underweight and overweight/obesity detection rates between rural left-behind and urban migrant middle school students.

\begin{tabular}{|c|c|c|c|c|c|c|c|c|c|c|c|c|}
\hline & \multicolumn{4}{|c|}{ Rural left-behind group $(\mathrm{n}=440)$} & \multirow[b]{2}{*}{$\mathrm{Z} / \chi^{2}$} & \multirow[b]{2}{*}{$P$} & \multicolumn{4}{|c|}{ Urban migrant group $(\mathrm{n}=513)$} & \multirow[b]{2}{*}{$Z / \chi^{2}$} & \multirow[b]{2}{*}{$P$} \\
\hline & $\mathrm{n}$ & Underweight & Normal & $\begin{array}{c}\text { Overweight/ } \\
\text { obese }\end{array}$ & & & $\mathrm{n}$ & Underweight & Normal & $\begin{array}{c}\text { Overweight/ } \\
\text { obese }\end{array}$ & & \\
\hline Sex & & & & & $-3.185^{\star}$ & 0.001 & & & & & $-0.028^{*}$ & 0.978 \\
\hline Male & 226 & $42(18.6)$ & $161(71.2)$ & $23(10.2)$ & & & 272 & $25(9.2)$ & $138(50.7)$ & $109(40.1)$ & & \\
\hline Female & 214 & $33(15.4)$ & $167(78.0)$ & $14(6.6)$ & & & 241 & $9(3.7)$ & $181(75.1)$ & $51(21.2)$ & & \\
\hline Age (years) & & & & & $1.912^{\#}$ & 0.591 & & & & & $1.960^{\#}$ & 0.581 \\
\hline 12 & 79 & $19(24.1)$ & $50(63.3)$ & $10(12.6)$ & & & 152 & $11(7.2)$ & $88(57.9)$ & $53(34.9)$ & & \\
\hline 13 & 103 & $14(13.6)$ & $82(79.6)$ & $7(6.8)$ & & & 168 & $11(6.5)$ & $103(61.3)$ & $54(32.1)$ & & \\
\hline 14 & 116 & $17(14.7)$ & $87(75)$ & $12(10.3)$ & & & 137 & $10(7.3)$ & $86(62.8)$ & $41(29.9)$ & & \\
\hline 15 & 142 & $25(17.6)$ & $109(76.8)$ & $8(5.6)$ & & & 56 & $2(3.6)$ & $42(75.0)$ & $12(21.4)$ & & \\
\hline
\end{tabular}

Note: numbers within parentheses indicate detection rates (\%); ${ }^{*}$ Mann-Whitney test; ${ }^{*}$ Kruskal-Wallis test. 
Table 2. Comparison of underweight and overweight/obesity detection rates of rural left-behind and urban migrant participants with different demographic characteristics.

\begin{tabular}{|c|c|c|c|c|c|c|c|c|}
\hline & \multicolumn{4}{|c|}{ Rural left-behind group $(\mathrm{n}=403)$} & \multicolumn{4}{|c|}{ Urban migrant group $(\mathrm{n}=479)$} \\
\hline & $\mathrm{n}$ & Underweight & $\chi^{2}$ & $P$ & $\mathrm{n}$ & Overweight/obese & $\chi^{2}$ & $P$ \\
\hline Fathers' educational level & & & 22.805 & $<0.001$ & & & 2.515 & 0.642 \\
\hline Primary or below & 65 & $23(35.4)$ & & & 38 & $13(34.2)$ & & \\
\hline Secondary & 99 & $24(24.2)$ & & & 198 & $73(36.9)$ & & \\
\hline High school/secondary technical or above & 239 & $28(11.7)$ & & & 243 & $74(30.5)$ & & \\
\hline Mothers' educational level & & & 16.639 & 0.002 & & & 4.133 & 0.388 \\
\hline Primary or below & 55 & $17(30.9)$ & & & 85 & $31(36.5)$ & & \\
\hline Secondary & 205 & $36(17.6)$ & & & 179 & $54(30.2)$ & & \\
\hline High school/secondary technical or above & 143 & $22(15.4)$ & & & 215 & $75(34.9)$ & & \\
\hline Monthly household income/yuan & & & 29.795 & $<0.001$ & & & 4.692 & 0.584 \\
\hline$\leq 2000$ & 126 & $39(31.0)$ & & & 5 & $2(40.0)$ & & \\
\hline $2001-5000$ & 32 & $7(21.9)$ & & & 134 & $42(31.3)$ & & \\
\hline $5001-8000$ & 74 & $12(16.2)$ & & & 177 & $59(33.3)$ & & \\
\hline$>8000$ & 171 & $17(9.9)$ & & & 163 & $57(35.0)$ & & \\
\hline Engagement in vigorous physical activity/week & & & 3.332 & 0.189 & & & 5.523 & 0.033 \\
\hline No & 214 & $33(15.4)$ & & & 361 & $131(36.3)$ & & \\
\hline Yes & 189 & $42(22.2)$ & & & 118 & $29(24.6)$ & & \\
\hline Engagement in moderate physical activity/week & & & 1.643 & 0.440 & & & 0.709 & 0.702 \\
\hline No & 276 & $47(17.0)$ & & & 410 & $140(34.1)$ & & \\
\hline Yes & 127 & $28(22.0)$ & & & 69 & $20(29.0)$ & & \\
\hline No. of hours spent watching television/day & & & 9.508 & 0.147 & & & 5.213 & 0.517 \\
\hline $0-1$ & 155 & $20(12.9)$ & & & 234 & $80(34.2)$ & & \\
\hline $2-3$ & 76 & $18(23.7)$ & & & 139 & $43(30.9)$ & & \\
\hline$>3$ & 17 & $4(23.5)$ & & & 28 & $9(32.1)$ & & \\
\hline Never & 155 & $33(21.3)$ & & & 78 & $28(35.9)$ & & \\
\hline No. of hours spent on a mobile phone/day & & & 12.933 & 0.012 & & & 5.602 & 0.231 \\
\hline$\leq 1$ & 204 & $44(21.6)$ & & & 244 & $86(35.2)$ & & \\
\hline $2-3$ & 131 & $25(19.1)$ & & & 199 & $66(33.2)$ & & \\
\hline$>3$ & 68 & $6(8.8)$ & & & 36 & $8(22.2)$ & & \\
\hline No. of fast-food meals/week & & & 1.691 & 0.792 & & & 0.492 & 0.974 \\
\hline$\geq 4$ & 9 & $1(11.1)$ & & & 16 & $5(31.3)$ & & \\
\hline $2-3$ & 246 & $46(18.7)$ & & & 388 & $129(33.2)$ & & \\
\hline$\leq 1$ & 158 & $28(17.7)$ & & & 75 & $26(34.7)$ & & \\
\hline No. of days on which breakfast was eaten/week & & & 5.588 & 0.232 & & & 2.527 & 0.640 \\
\hline$\geq 4$ & 350 & $69(19.7)$ & & & 417 & $139(33.3)$ & & \\
\hline $2-3$ & 36 & $4(11.1)$ & & & 51 & $16(31.4)$ & & \\
\hline$\leq 1$ & 17 & $2(11.8)$ & & & 11 & $5(45.5)$ & & \\
\hline
\end{tabular}

Note: numbers within parentheses indicate detection rates (\%). 
Table 3. Logistic regression analysis of correlations between family conditions and lifestyle behaviours with underweight and overweight/obesity among middle school students.

\begin{tabular}{|c|c|c|c|c|c|c|c|c|c|}
\hline & \multicolumn{4}{|c|}{ Rural left-behind group $(n=403)$} & & \multicolumn{4}{|c|}{ Urban migrant group $(\mathrm{n}=479)$} \\
\hline & $\beta$ & OR & $95 \% \mathrm{CI}$ & $P$ & & $\beta$ & OR & $95 \% \mathrm{CI}$ & $P$ \\
\hline Fathers' educational level & & & & & $\begin{array}{l}\text { Engagement in vigorous } \\
\text { physical activity/week }\end{array}$ & & & & \\
\hline Primary or below & 1.421 & 4.14 & $2.17-7.89$ & $<0.001$ & No & 0.558 & 1.75 & $1.09-2.80$ & 0.020 \\
\hline Secondary & 0.867 & 2.38 & $1.30-4.37$ & 0.005 & Yes & & 1 & & \\
\hline $\begin{array}{l}\text { High school/secondary } \\
\text { technical or above }\end{array}$ & & 1.00 & & & & & & & \\
\hline \multicolumn{10}{|l|}{ Mothers' educational level } \\
\hline Primary or below & 0.773 & 2.17 & $1.10-4.27$ & 0.026 & & & & & \\
\hline Secondary & -0.099 & 0.91 & $0.50-1.64$ & 0.74 & & & & & \\
\hline $\begin{array}{l}\text { High school/secondary } \\
\text { technical or above }\end{array}$ & - & 1.00 & & & & & & & \\
\hline \multicolumn{10}{|l|}{ Monthly household income } \\
\hline$\leq 2000$ & 1.404 & 4.07 & $2.15-7.73$ & $<0.001$ & & & & & \\
\hline $2001-5000$ & 0.894 & 2.44 & $0.91-6.57$ & 0.076 & & & & & \\
\hline $5001-8000$ & 0.491 & 1.63 & $0.72-3.70$ & 0.239 & & & & & \\
\hline$>8000$ & & 1.00 & & & & & & & \\
\hline
\end{tabular}

Note: $\mathrm{OR}=$ odds ratio, $\mathrm{CI}=$ confidence interval.

\section{Discussion}

The results indicated that the nutritional status of rural left-behind middle school students in Shangrao and urban migrant middle school students in Shanghai were mainly manifested as a high underweight detection rate and a high overweight/obese detection rate, respectively, which is consistent with previous results (Ji \& Lin, 2018; Yin, Zheng, Tao, Zhang, \& Hu, 2015). Despite the increase in resource inputs and the comprehensive implementation of the Targeted Poverty Alleviation Strategy by the Chinese government in rural areas, there is still much room for improvement in the health levels of rural residents. Although the numbers of children and adolescents experiencing growth delays (Ekekezie, Odeyemi, \& Ibeabuchi, 2012; Oninla, Owa, Onayade, \& Taiwo, 2007) and maldevelopment (Shalini, Murthy, Shalini, Dinesh, Shivaraj, \& Suryanarayana, 2014; Huang, Zhong, Li, Xu, Zhang, Feng, Yang, Bo, \& Deng, 2015) have declined substantially, underweight individuals still account for a significant proportion of the population-with relevant data showing an underweight prevalence of approximately $10 \%$ in rural children and adolescents aged $6-17$ years. The issue of overweight/obesity in urban migrant children and adolescents has also been discussed in many studies, which identified the increase in household income and changes in lifestyle behaviours as the main risk factors of overweight/obesity (Zhang, Cong, \& Fang, 2007; Tao \& Yin, 2015). 
Our results showed that underweight in the rural left-behind middle school students was negatively correlated with parental educational level and monthly household income (Dang \& Yan, 2007); i.e. lower educational levels and monthly household incomes associated with higher underweight detection rates. The per capita monthly household income was the main family factor that significantly affected the health behaviours of children, as individuals with higher socioeconomic statuses have greater abilities and motivation to maintain a healthy lifestyle. Fathers with a low educational level are generally less educated, lack basic knowledge about nutrition and food safety, and provide less guidance to their children (Li, Zhang, \& Zhang, 2019); similarly, mothers with a low educational level will also affect the health behaviours of their children and lead to a lack of knowledge about nutrition and health maintenance. Higher parental educational levels usually result in the attainment of higher health knowledge and behaviour scores by children (Li, Zhang, \& Zhang, 2019). A low household income affects families' purchasing ability and limits health-related expenditures, thereby directly affecting the health behaviours of family members.

Our results also demonstrated that overweight and obesity in the urban migrant middle school students in Shanghai was associated with engagement or non-engagement in vigorous physical activity on a weekly basis. Besides promoting the growth and development of children, vigorous physical activity is also of great significance to the enhancement of physical functions, control of overweight and obesity, and prevention of cardiovascular diseases. Studies have shown that inadequate physical activity is a known risk factor of overweight and obesity in adolescents, and children who engage in frequent vigorous physical activity have a low tendency to become overweight or obese (Zhou \& Cheah, 2015).

\section{Conclusion}

In sum, we effectively compared the nutritional status of rural left-behind and urban migrant middle school students. However, the selection of Shangrao and Shanghai to represent the rural left-behind and urban migrant regions limits our ability to generalise our results at the nationwide level. Therefore, certain biases may exist in our reported results, and future researchers should address this. And this is only a cross-sectional study, and it would be better to do a follow-up study in the future to be more convincing.

\section{Acknowledgements}

The authors acknowledge the help of the cohort study investigators from the Graduate School of Physical Education, Yangtze University (Jingzhou, Hubei), specifically Y. R. Xie, D. Q. Zhang, H. Liu and Jing Ma as well as the principals of the schools involved in this study.

\section{Author Contributions}

Conceptualization, J. L. and Y. S.; Methodology, Y. L. (Yu Lou) and J. X.; Soft- 
ware, F. S.; Validation, Y. L. (Yu Lou) and J. X.; Formal Analysis, F. S.; Investigation, C. M. and M. Y.; Resources, Y. S.; Data Curation, Y. L. (Yuqiang Li); Writing, Original Draft Preparation, Y. S.; Writing Review \& Editing, Y. S. and J. L.; Visualization, Y. S.; Supervision, Y. S.

\section{Ethics and Consent}

This study was approved by the Ethics Committee of Yangtze University (China). Before conducting the basic situation survey, the purposes of the survey and relevant precautions protecting their anonymity were described to all participants. The students and their guardians voluntarily participated in the survey and verbal informed consent was obtained from them.

\section{Conflicts of Interest}

The authors declare no conflicts of interest regarding the publication of this paper.

\section{References}

Dang, S. N., \& Yan, H. (2007). Optimistic Factors Affecting Nutritional Status among Children during Early Childhood in Rural Areas of Western China. Chinese Journal of Preventive Medicine, 41, 108-114.

Duan, C. R., \& Yang, G. (2008). The Left-Behind Children in Rural China. Population Research, 32, 15-25.

Ekekezie, O. O., Odeyemi, K. A., \& Ibeabuchi, N. M. (2012). Nutritional Status of Urban and Rural Primary School Pupils in Lagos State, Nigeria. West African Journal of Medicine, 31, 232.

Fu, D., \& Chen, L. Q. (2018). Experimental Study on the Group Sports of the Left-Behind Children in Rural Areas. 6 Journal of Hunan Institute of Science and Technology (Natural Sciences), 31, 5-73.

Hootman, J. M. (2009). 2008 Physical Activity Guidelines for Americans: An Opportunity for Athletic Trainers. Journal of Athletic Training, 44, 5-6. https://doi.org/10.4085/1062-6050-44.1.5

Hu, Z. T. (2019). Family-School Collaboration Model for the Correction of Undesirable Behaviour in Rural Left-Behind Children. Nanchang: Jiangxi University of Finance and Economics.

Huang, Y., Zhong, X. N., Li, Q. Y., Xu, D., Zhang, X. L., Feng, C., Yang, G. X., Bo, Y. Y., \& Deng, B. (2015). Health-Related Quality of Life of the Rural-China Left-Behind Children or Adolescents and Influential Factors: A Cross-Sectional Study. Health and Quality of Life Outcomes, 13, 29. https://doi.org/10.1186/s12955-015-0220-x

Ji, M. M., \& Lin, Q. (2018). Current Status of Nutrition, Growth and Development and Its Influencing Factors among Rural Left-Behind Children in China. Practical Preventive Medicine, 25, 1277-1281.

Jiang, B., \& He, W. X. (2019). The Influencing Mechanism and Supporting Path of Cultural Adaptation of Urban Migrant Children: A Positive Psychological Perspective. Research in Educational Development, 39, 78-84.

Jing, X. X. (2019). Study on the Relationship between Loneliness, Coping Style and Self-Harmony of Left-Behind Children in Rural Areas. Baoding: Hebei University. 
Kuang, H. D., \& Xu, L. W. (2017). Definitions and Inter-Relationships of Mobile, Left-Behind and Migrant Children. Youth \& Children Research and Practice, 32, 28-33.

Lei, Y. (2014). Psychological Problems of Rural Left-Behind Children and Countermeasures: An Analysis of a Sample from Hunan, Guangxi, Jiangxi, Zhejiang, Anhui and Hebei Provinces in China. Beijing: Chinese Academy of Forestry.

Li, B. F. (2005). The Mental Health Problem of the "Rear Children" in Village and Its Meddle. Education Exploration, 25, 82-83.

Li, P. H., \& Wang, H. T. (2018). Causes and Countermeasures of Undesirable Behaviour among Left-Behind Children in Rural Primary Schools: A Preliminary Investigation. Education for Chinese After-School, 12, 12.

Li, P., Zhang, T. C., \& Zhang, F. L. (2019). Nutritional Status and Influencing Factors of Left-Behind and Non-Left-Behind Children in Rural Yongzhou. Modern Preventive Medicine, 46, 2735-2739+2752.

Liu, D. Y., Yu, X. B., Wang, Y. C., Zhang, H. Q., \& Ren, G. F. (2014). The Impact of Perception of Discrimination and Sense of Belonging on the Loneliness of the Children of Chinese Migrant Workers: A Structural Equation Modeling Analysis. International Journal of Mental Health and Addiction, 8, 52. https://doi.org/10.1186/1752-4458-8-52

Liu, X., Zhang, Y. B., Li, R. Q., Zhai, J. H., \& Xu, Y. (2011). Survey of Psychological and Behavioral Problems of Left-Behind Junior Middle School Students in Rural Area. China Tropical Medicine, 11, 839-841.

Liu, Y., \& Dai, B. (2019). Relationships of Family-Related Factors with Overweight and Obesity in School-Age Children and Adolescents. Chinese Journal of Public Health Engineering, 18, 716-717.

Lu, J. K., Yin, X. J., Deng, Y. Q., \& Ji, L. (2017). High Socioeconomic Status and Key Risk Factors of Overweight and Obesity among Rural-to-Urban Migrant 7 - 10y-Old Children in Shanghai, China. Iranian Journal of Public Health, 46, 420-421.

Mou, J.S., Luo, J. Y., Li, Y. P., Shuai, Z. R., \& Liu, X. H. (2009). Study on the Nutritional Status and Determinants among Rural Stranded Children in China. Chinese Journal of Epidemiology, 30, 439-443.

National Health and Family Planning Commission of the People's Republic of China (2014). Screening Standard for Malnutrition of School-Age Children and Adolescents. WS/T 456-2014.1-7. Beijing.

National Health and Family Planning Commission of the People's Republic of China (2018). Screening Standard for Overweight and Obesity among School-Age Children and Adolescents. WS/T586-2018. Beijing.

Oninla, S. O., Owa, J. A., Onayade, A. A., \& Taiwo, O. (2007). Comparative Study of Nutritional Status of Urban and Rural Nigerian School Children. Journal of Tropical Pediatrics, 53, 39-43. https://doi.org/10.1093/tropej/fml051

Shalini, C. N., Murthy, N. S., Shalini, S., Dinesh, R., Shivaraj, N. S., \& Suryanarayana, S. P. (2014). Comparison of Nutritional Status of Rural and Urban School Students Receiving Midday Meals in Schools of Bengaluru, India: A Cross Sectional Study. Journal of Postgraduate Medicine, 60, 118. https://doi.org/10.4103/0022-3859.132309

Tao, X., \& Yin, X. J. (2015). A Comparative Study on the Nutritional Status of the Left behind Children, Migrant Children and Urban Children. Sports \& Science, 36, 112-120.

$\mathrm{Tu}$, S. (2016). Health Status of Rural Children in Destitute Areas of Hubei Province and Its Influencing Factors. Wuhan: Huazhong University of Science and Technology.

Wang, J., Liu, K., Zheng, J., Liu, J. L., \& You, L. M. (2017). Prevalence of Mental Health Problems and Associated Risk Factors among Rural-to-Urban Migrant Children in 
Guangzhou, China. International Journal of Environmental Research and Public Health, 14, 1385. https://doi.org/10.3390/ijerph14111385

Wang, X. Y. (2009). The Bad Behaviors of and the Countermeasures on the Children Remaining in Rural Areas-Take Bishan County in Chongqing for Example. Journal of Chongqing University of Arts and Sciences, 28, 70-73.

Wei, P., \& Zhang, Y. (2018). Development of Positive Psychological Traits in Urban Migrant Children. Journal of Hefei University, 35, 125-130.

Wu, H. H., Qiao, C., \& Hao, M. J. (2019). Relationship between Family Behavior Factors and Overweight/Obesity in Primary and Junior School Students. Chinese Journal of School Health, 40, 1001-1004.

Xiao, Y., \& Zeng, T. D. (2014). The Review on Trailing Children's Mental Health. Journal of Mudanjiang Normal University, 3, 123-124.

Yin, X. J., Zheng, D. H., Tao, X., Zhang, C. J., \& Hu, R. (2015). Physique and Nutrition Status of Urban and Migrant Children in Yangtze River Delta Region. Journal of Shenyang Sport University, 34, 97-103.

Zhang, F., Cong, Y. I., \& Fang, G. H. (2007). Survey of Nutritional Status of Primary School Pupils in Rural Areas of Longhua District, Haikou City in 2007. China Tropical Medicine, 11, 105.

Zhang, X. W. (2018). Community Services Targeted towards the Migrant Children of Migrant Workers in Urban China. Modern Communication, 21, 6-57.

Zhou, L. (2018). Influence of Metacognition on the Psychological Health of Migrant Children in Primary Schools. Shanghai: Shanghai Normal University.

Zhou, N., \& Cheah, C. S. L. (2015). Ecological Risk Model of Childhood Obesity in Chinese Immigrant Children. Appetite, 90, 99-107.

https://doi.org/10.1016/j.appet.2015.02.028 